This item was submitted to Loughborough's Research Repository by the author.

Items in Figshare are protected by copyright, with all rights reserved, unless otherwise indicated.

\title{
Design vs. the design industry
}

PLEASE CITE THE PUBLISHED VERSION

https://doi.org/10.2752/144871314X14159818597513

\section{PUBLISHER}

(c) Bloomsbury. Published by Taylor and Francis

\section{VERSION}

AM (Accepted Manuscript)

\section{PUBLISHER STATEMENT}

This work is made available according to the conditions of the Creative Commons Attribution-NonCommercialNoDerivatives 4.0 International (CC BY-NC-ND 4.0) licence. Full details of this licence are available at: https://creativecommons.org/licenses/by-nc-nd/4.0/

\section{LICENCE}

CC BY-NC-ND 4.0

\section{REPOSITORY RECORD}

Boehnert, Joanna. 2019. “Design Vs. The Design Industry”. figshare. https://hdl.handle.net/2134/35078. 


\title{
Design vs. The Design Industry
}

\author{
Dr. Joanna Boehnert \\ Center for Science and Technology Policy Research \\ Cooperative Institute for Research in Environmental Sciences \\ 1333 Grandview Avenue \\ University of Colorado \\ Boulder, Colorado, USA
}

This paper will argue that designers are currently not able to effectively address contemporary environmental and social problems due to the systemic priorities of the design industry. Despite the fact that emergent cognitive and perceptual capacities enable a greater understanding of complexity and design practice evolves creating potential for social and technological innovation, the structural dynamics of the design industry reproduce conditions of deep unsustainability. In this paper "design" is theorized as the professional practice of creating new products, buildings, services and communication. This is a broader practice than the work that is produced within the "design industry". The design industry operates according to highly reductive feedback generated by capitalism that systemically ignores signals from the ecological and social systems. The exclusive focus on profit and quantitative economic growth results in distortions of knowledge and reason thereby undermining prospects for the design of long-term prosperity. Redirected design practice could be an antidote to this dilemma by transforming the system that determines what is designed. This paper contributes an overview of the political and economic dynamics that are relevant to designers concerned with sustainability.

\section{Keywords}

Sustainable design; epistemology; environment; capitalism

Dr. Joanna Boehnert is a visiting research fellow at the Center for Science and Technology Policy Research in the Cooperative Institute for Research in Environmental Sciences at the University of Colorado in Boulder. Here she is mapping climate communication and issues of the green economy. She completed her AHRC-funded PhD in 2012 at the University of Brighton in 2012, is founding director of EcoLabs and is currently writing a book titled Design/Ecology/Politics for Bloomsbury Academic. 


\section{Design vs. The Design Industry}

As the professional practice of creating new products, buildings, services, infrastructure and communication, design manifests the creative vision of individual designers for solutions to meet human needs and desires. As a de-centralized discovery process using tacit knowledge to bring forth new scenarios, design addresses problems and creates solutions. As technology and communication practices evolve, designers learn new skills and abilities thereby providing the basis for greater social and technological innovation. Within an increasingly visual and web-based culture, new cognitive and perceptual capacities enable a greater understanding of complexity, context and system dynamics. The phenomenon of emergence is significant for design practice because it describes a process of selforganization that results in the creation of entirely new properties. Emergent properties are designers' own new relational capacities that enable greater contextual understanding and new abilities to respond to complex levels of causality within networks and dynamic systems. These new abilities support humankind's collective capacity to attend to sustainability challenges.

Unfortunately, despite these emergent skills, this paper argues that designers are not able to effectively address contemporary problems in regards to sustainability due the systemic priorities of the design industry.

This paper proposes that the practice of design, understood as a socially beneficial activity engaged with building a better world, is integrally in conflict with the design industry due to the epistemological, ontological and ideological assumptions embedded into and reproduced by capitalism, the economic system that determines the priorities of the design industry. While the concept of design as involved with creating a better world is the dominant rhetoric in the industry and reflects the stated intentions of many if not most designers, designers also simultaneously have other, often obscured and conflicting intentions, determined by the systemic priorities of design industry. This analysis of the systemic dynamics of design and the design industry draws on systems, social, political and philosophical theory. Systemic failure is evidenced by social and environmental sciences, with specific examples referred to below. The contribution of this work is in bringing insights from economic, political and ecological theory into design theory to describe why it is that we are not currently solving the environmental problem by design.

This paper describes the practice of design and the design industry as oriented towards different goals. This proposition is based on both the explicit intentions of designers and the design industry as well as an analysis of the systemic behavior of each. The design industry is a subsystem of the economic system, i.e. 
capitalism, oriented towards the accumulation of profit and economic growth. Design agencies function as instrumental organizations directing designers toward the priorities of the design industry. The capitalist economic system determines the priorities of the design industry, design agencies and ultimately even individual designers. These priorities are reinforced by financial rewards for certain tasks. The organization of economic and social relations is determined by the powerful dynamics of the capitalist system. Designers' activities are oriented towards these systemic priorities in the design of products, communications and buildings that are profitable.

Meanwhile, ecological theorists have exposed the manner in which the western philosophical tradition has inherited a legacy of denying and dismissing the lifesustaining services provided by the natural world (Merchant 1980; Shiva 1988; Sterling 2001; Plumwood 2002; Capra 2003; Santos 2007). This error in ontology and epistemology constitutes a crisis of reason (Plumwood 2002) wherein we systemically devalue and/or ignore the ecological context that makes our lives possible. These errors in philosophical premises have led to a situation where humankind has designed of ways of living with little or no regard for the ecological consequences of industrial processes. Physical scientists have documented the resulting crises across the earth sciences. Scientists warn: "human activity is putting such strain on the natural functions of Earth that the ability of the planet's ecosystems to sustain future generations can no longer be taken for granted" (Assadourian 2010: 4). This warning is reinforced by multiple international collaborations involving thousands of scientists (MA Board of Reviewers 2005; Rockstrom et al. 2009; IPCC 2013). The stakes could not be higher. Environmental problems ultimately emerge from a lack of understanding and concern for the ecological consequences of human activities. While many designers now have the emerging systemic awareness to address complex problems including environmental problems, progress is obstructed by the reductive goals of the design industry oriented towards the goals of capitalism based on the denial of ecological context.

\section{Design as an Emergent Practice Supporting Sustainability}

Design as a practice emerges out of the creative capacities of thousands of individual designers responding to local conditions and evolving greater skills of bringing forth inventive solutions for the benefit of humankind (and occasionally the wider ecological system). Design is an applied transdisciplinary field in pursuit of practical outcomes, a knowledge building process that combines thinking and doing. Design encompasses a wide spectrum of problem solving activities concerned with the creation of new artifacts, communications, buildings and new ways of living. Over recent decades the scope of design problems has been widened to involve a shift from designing products to designing systems and 
processes. Meanwhile, designers have developed new skills that enable them to respond to increasingly complex problems.

Design practice has also functioned as a means of expanding knowledge: "there are circumstances where the best or only way to shed light on a proposition, a principle, a material, a process or a function is to attempt to construct something or enact something, calculate, explore, embody or test it" (Archer 1995: 11). Design is a means of envisioning and creating new realities and new ways of living. Design thinking and systems thinking offer strategies for strategic planning. As a professional practice, design is uniquely positioned to engage with reality in a dynamic process of moving from theory to practice and moving between disciplines and sectors to facilitate transdisciplinary actions.

Design is a process where tacit knowledge is used to bring forth solutions. Design evolved from the tradition of craftsmanship wherein persons held practical skills for making new artifacts. Design continues to be a discovery process that occurs in decentralized spaces as individual designers use tacit skills, strategies and tools to address local problems. Accumulated tactic knowledge is used for the purposes of solving increasingly complex problems. For example, a communication designer has tacit knowledge manifested as drawing skills, developed through years of practice and study of master draftspersons. These skills can help a community understand proposals by an architectural development through a series of visualizations. Design can be understood as the process of embodying social rules in new communications, artifacts and spaces, thereby embodying and reproducing social rules and social relations while solving problems.

Design is a field of practice evolving to increasing levels of complexity as globalized networks and technologies become more sophisticated. As communication media change, humankind develops new communicative capacities. Media theorists and cultural historians describe how consciousness evolves as communication processes and media change (McLuhan 1964; Rushkoff 1996). Within an increasingly visual culture the emergence of greater systemic thought is evident (Barry 1997; Horn 1998). Visual communication is increasing human capacity for greater understanding of complexity and dynamics systems (Chabris \& Kosslyn 2005), as is digital communication. These tools enable human capacities for negotiating complexity. Emergent relational capacities support a new understanding of connections, networks and complex levels of causality. As these abilities evolve our potential collective capacities to attend to sustainability challenges are enhanced.

Unfortunately, the complexity characterizing contemporary problems is rarely adequately addressed by design. While designers may want to reveal and respond to complex environmental priorities, this work often involves confrontations with powerful vested interests and cultures of denial. Like all matters in regards to sustainability, the onus of using intellectual and other resources toward the well 
being of people and planet sits at odds with the demands of short-term profit incentives.

Emergent cognitive capacities and perceptual practices (such as critical, reflective systems thinking) potentially have radical implications for the design of innovative, prosperous and sustainable ways of living. The dissemination of knowledge within the design industry creates feedback loops that influence the capacities of designers to resolve more complex problems. Design evolves through knowledge sharing of successful design interventions. Good design solutions are imitated, successful strategies copied and these new projects can create more effective solutions. The emergence of new systemic capacities creates awareness of the interdependence and the interconnected nature of contemporary problems and some designers are increasingly aware of the ecological context and are potentially able to respond with sustainable solutions.

\section{Tensions, Priorities and Contradictions in the Design Industry}

Despite these encouraging signs, the emergent properties described above are not resulting in effective solutions to the environmental crisis. While designers can design sustainable solutions, the global situation (in regards to climate change, biodiversity loss and other ecological crises) continues to get worse rather than better. Humankind reproduces conditions of unsustainability and designers contribute to unsustainable ways of living. Instead of harnessing new abilities to solve social and ecological problems, the design industry harnesses the vision, skills and capacities of designers to serve its own goals, i.e. the creation of economic profit. Thus, as the technological and industrial capacities of civilizations become more powerful, designers are increasingly implicated with ecologically and socially harmful (put profitable) design activities. Design straddles the borders of various systems: the economy (a physical and socially constructed system) and the ecological system (a biological and geophysical system). The need for better understanding of the implications and ecological consequences of design practice is evident but feedback mechanisms are perverted by distortions in knowledge and reason (described shortly). Tensions between systems multiply as the economic system's reductive focus on profit to the exclusion of all other priorities creates increasingly severe social and environmental problems.

Design as a practice is oriented towards a wider set of goals and different values than those of the design industry due to the fact that some individual designers can and do notice and attempt to address problems outside the scope of market priorities. The design industry is a subsystem of the economic system that is capitalist. The systemic bias of capitalism is the creation of economic profit (for those with the capital to invest) and quantitative economic growth. Herein lies a basic impasse; design must operate according to reductive feedback (based on the priorities determined by capitalism) as opposed to the feedback from the system in which the economic system is situated and upon which it is dependent (the 
ecological system). Whereas designers may recognize the larger context, the design industry reduces its systemic goals to the accumulation of profit and market growth. With this reductive focus, the market ignores as much as possible the ecological and social basis of its own context. The feedback from the market is impersonal and simple, but wellbeing for the Earth and the majority of its inhabitants is much more complex.

While describing the design industry as oriented towards profit and economic growth is a simplification of its dynamic, the dominant characteristic of business in capitalism is the pursuit of profit. Design firms that ignore this "imperative" struggle to survive. The reductive focus on profit as the highest priority conflicts with the priorities and complexities of the ecological context in which the economic system is embedded. Since the ecological system is the context of capitalism, the ultimate "imperative" is to sustain this ecological context on which we depend.

Ecological and social values struggle to compete in a market economy since these priorities are systemically devalued by market mechanisms that reward those who can get the most human and ecological "resources" for the least investment. For examples, those who value the preservation of nature can donate their money to charities, but in a market-dominated economy these charities are so marginalized they are not able to stop the rapid destruction of ecological spaces and individual species. Capitalism is dependent on an increasing flow of natural resources, resources that exit the economic system as waste, including greenhouse gases. Organizations working within capitalism organize flows of information to suit the priorities of industry. Social and ecological priorities are systemically undermined as design is oriented towards increasing market growth at the expense of all other priorities.

Capitalism's reductive focus on economic profit and quantitative growth does not reflect the complexity of systemic conditions or the needs of the ecological system. Thus the design industry, constrained by capitalism, is not (and cannot) create a foundation for long-term prosperity within the current context. The design industry relies on profit as feedback to establish value but profits do not reflect ecological stability, resilience, equity, wellbeing or happiness for the vast majority. Profits come from serving the needs of those with the ability to pay, while getting as many ecological and social "resources" as cheaply as possible. A narrow focus on economic profit excludes a holistic appraisal of values and encourages short-term thinking and waste of ecological and human "resources". Even our language becomes distorted around the narrow focus of profit; we know that neither nature nor people are inherently "resources" but have value in their own right outside of their function as a source of profit. The nature of the market is to grow and consume everything to suit its needs: our language, our values and our ideas about what can and cannot be an economic transaction. The emphasis on profit in an international neoliberal capitalist system based on infinite growth is that transnational capital will continue to grow and swallow up everything in its wake 
until there is nothing left to use. Evidence will take the form of lost species, destroyed rainforests and an unstable climate system; complex ecological systems and species that have evolved over millions of years that are being degraded, destroyed, destabilized and/or made extinct in a matter of a few decades.

\section{Reproducing Epistemological Error by Design}

When things are not working properly, it is often necessary to look into the philosophical roots of our habitual practices. Our understanding of reality, our way of knowing or our epistemology leads to particular types of practice in business, finance, culture, education, politics and design. When our ideas conflict with the way that the world actually works, we make dysfunctional systems. In the seminal book Steps to an Ecology of Mind, Gregory Bateson first proposed that the dominant epistemological position is a poor reflection of reality itself: "most of us are governed by epistemologies we know to be wrong" (1972: 493). This error arises from a lack of understanding of the order of nested systems. A nested system refers to the order of layers in a system, since "life is an integrated process of nested living systems" (Günther \& Folke 1993: 257). Dysfunction arises when the relationship between the nested layers breaks down. Such is the case with the current relationships between economic, social and ecological systems, wherein the economic system is not designed as a sub-system of the ecological system (Daly 2008: 1998). Plainly, "socio-economic systems not only need, but also depend on natural resources and ecological services for evolution and survival" (Daly 2008: 272). Bateson and other ecological theorists claim that our epistemological tradition denies ecological context. This error has dramatic implications. A subsystem embedded within a larger system that ignores its context functions as a cancer or a parasitic growth destroying its host. Such is the relationship between the current economic system and the ecological system as illustrated in the figure below. 


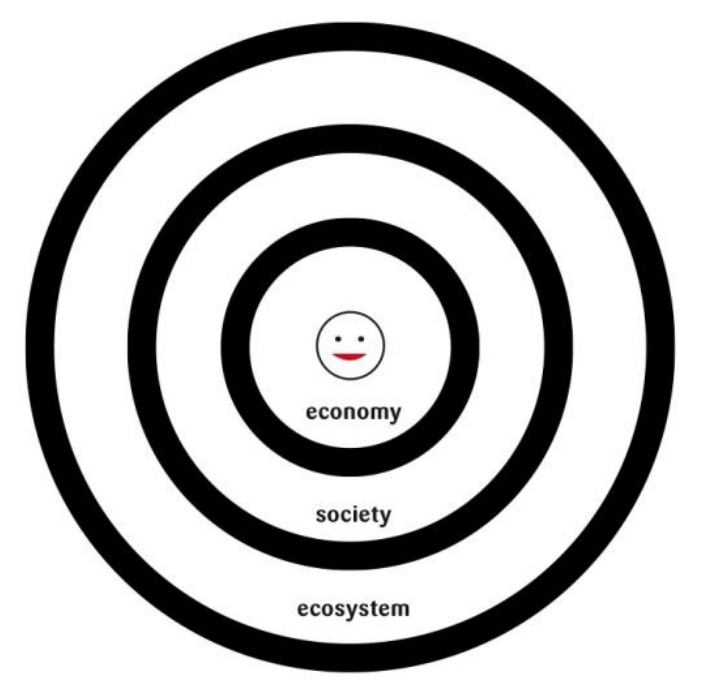

Fig 1. The ecosystem, society \& economy as nested systems. EcoLabs 2014

Future prosperity (and ultimately even survival) now depends on our capacity to design for whole systems. In order to do this we must understand ourselves as part of a larger ecological system on which we depend for survival. The failure of the current economic system to reflect the priorities of the ecological and social systems in which it is embedded constitutes a major error of basic premises and a severe neglect of context. Bateson claims our entire epistemological premises are in error:

the last 100 years or so have demonstrated empirically that if an organism or aggregate of organisms sets to work with a focus on its own survival and thinks that is the way to select its adaptive moves, its 'progress' ends up with a destroyed environment. If an organism ends up destroying its environment, it has in fact destroyed itself (1972: 457).

Ecological theory suggests that as ecological beings we are embedded and mutually dependent on the rest of the natural world but our understanding of reality does not reflect this basic geophysical reality. The narrowing down of our epistemology, ontology and ideology to reflect only our own interests or even the interests of our own species and the instrumental processes we use to do this are at the root of contemporary environmental problems. The radical disconnection from the ecological world and the forgetting of nature constitutes a severe epistemological error.

The erroneous premise of independence from the environment is encoded in the objects, communication and cities we design and build. Bateson describes the "self-validating power of ideas: the world 'partly becomes - comes to be - how it is 
imagined'" (1980: 223). While no rational society rewards members to undermine its existence, capitalism encourages individual actors to exploit ecological and social resources by reducing all values to economic profitability.

The underestimation of complexity and denial of the ecological world on which we depend for subsistence constitutes a major distortion of reason. A crisis of reason results from the systemic devaluing of nature. The problem is severe: "for modernist societies capable of very major and rapid ecological impacts, to lack adequate ecological correctiveness is like having a vehicle which is capable of going very fast but has a fault or poorly developed brakes or steering system" (Plumwood 2002: 67). Denying and destroying the context of our existence is the hallmark of an irrational society. Sustainability is literally impossible within this irrational, erroneous way of thinking and acting.

Epistemological error is encoded into cultural artifacts that reflect the perspectives, worldviews and priorities of their producers. Thus the design industry functions as part of feedback loops that reinforce epistemological error, reproduced by design. These philosophical problems become increasingly dangerous in civilizations with advanced technologies, where Bateson explains that the "likelihood of survival will be that of a snowball in hell" (1972: 468). Thus while systemic understanding is developing to respond to complex problems, design cannot respond effectively due to the systemic priorities of capitalism stuck in an old paradigm characterized by epistemological error.

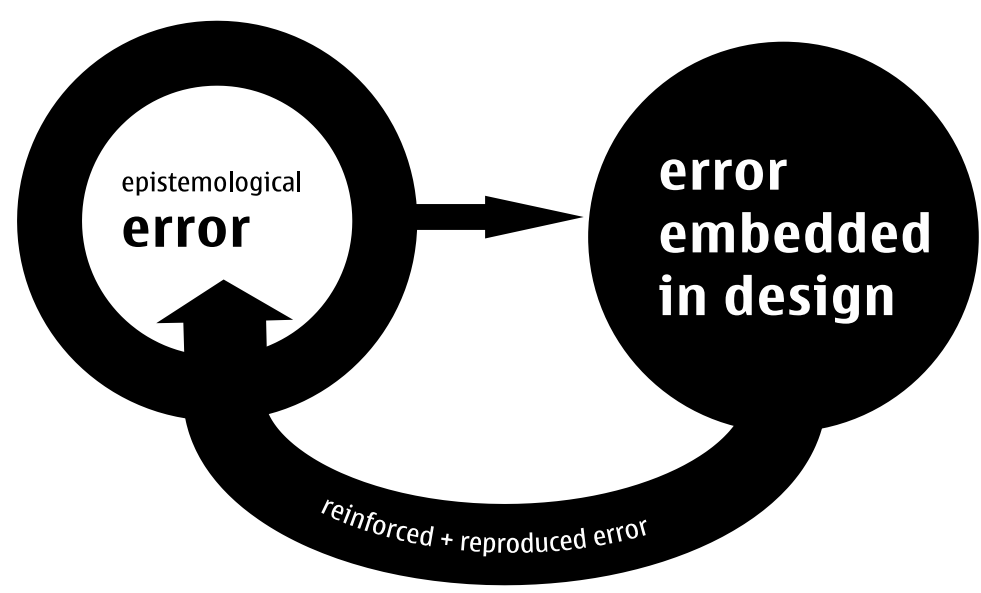

Fig 2. Epistemological error reproduced by design. EcoLabs 2014

\section{Communication Failure in Feedback Systems}

The ecological system was here before and will be here long after the human made economic system. Despite this fact, the current economic system was not designed 
to acknowledge the needs of the ecological system. Clearly capitalism was not designed in a studio but evolved over time reflecting philosophical assumptions deeply-rooted within political decisions based on abstract economic theory. Economic decisions over the past two centuries have been based on a certain type of economic theory, that of market liberalism, i.e. the belief that (supposedly) selfregulating markets are the best means of organizing an economy. In 1944 Karl Polanyi exposed the myth of the free market (Stiglitz 2001:xiii) by describing how laissez-faire economics was planned. Far from being a natural state of affairs, laissez-fair free markets required "statecraft and repression to impose the logic of the market and its attendant risks on ordinary people" (Block 2001: xxvii). Polanyi wrote "There was nothing natural about laissez-faire; free markets could never have come into being by merely allowing things to take their course" (Polanyi 1944: 145). The current economic system is the result of political decision-making based on economic theory that dangerously and ill-logically ignores the fact that the economic system is embedded and entirely dependent on its social and ecological context. Before the advent of market liberalism (starting with the Wealth of Nations in 1776) the economic order was always of mere function of the social order (Polanyi 1944: 74). Market liberalism was the first economic system in history to subordinate both the social and ecological systems to the market. Polanyi's description of the disembedded economy is a key contribution to social thought that reminds us that the current economic system was created with no regard for the ecological context in which it is situated.

More recently, green and ecological economists note that a narrow commitment to short-term profit over all other types of feedback cannot create robust economic systems over the long-term. An economic system focused on profit and everincreasing GDP undermines opportunities for long-term prosperity. This argument is no longer a radical green idea. Mechanical engineer Professor Roderick Smith described the consequences of the fixation with quantitative economic growth in a noteworthy speech at the UK Royal Academy of Engineering:

relatively modest annual percentage growth rates lead to surprisingly short doubling times. Thus, a 3\% growth rate, which is typical of the rate of a developed economy, leads to a doubling time of just over 23 years. The $10 \%$ rates of rapidly developing economies double the size of the economy in just under 7 years. These figures come as a surprise to many people, but the real surprise is that each successive doubling period consumes as much resource as all the previous doubling periods combined. This little appreciated fact lies at the heart of why our current economic model is unsustainable (2007: 17).

The expansive dynamics of the economic system locked into quantitative growth are fundamentally in conflict with the ecological system on which we all depend. Humanity's collective ecological footprint exceeds the Earth's biocapacity (the area available to produce renewable resources and absorb greenhouse gases) by 50 per cent (WWF 2010: 8). We are shrinking the available biocapacity on which we 
depend. Earth scientists warn of the extreme danger of this situation. From an economic perspective, The Stern Review (2007) clarifies the serious threat presented by climate change.

Capitalism depends on endless quantitative economic growth yet this growth is ultimately constrained by the relatively finite nature of the planet's natural resources (biocapacity). Ecological economist Herman Daly points out that growth's first literal dictionary definition is "to spring up and develop to maturity" and "thus the very notion of growth includes some concept of maturity or sufficiency, beyond which point physical accumulation gives way to physical maintenance" (Daly quoted in Simms, Johnson \& Chowla, 2010: 4). At maturity growth must give way to a state of dynamic equilibrium. Dynamic equilibrium used within this context refers to an economic system that exists "within ecosystem limits but where there is constant change, shifting balances and evolution" (Ibid: 121). The economy must permit "qualitative development but not aggregate quantitative growth" (Daly 2008: 1). Despite the importance of these insights, capitalism remains blind to geophysical realities and continues to use the discredited concept of GDP to measure progress. GDP was never intended be used in such a simplistic fashion. Simon Kuznets, the creator of the GNP/GDP metric "warned in 1934 that such a limited, onedimensional metric should not be used as an index of overall social progress" (Simms, Johnson \& Chowla 2010: 4). Capra and Henderson's report Qualitative Growth for the Institute of Chartered Accountants in England \& Wales describes how as living systems mature their growth processes shift from quantitative to qualitative growth. The report proposes a new concept of quality within market growth:

Instead of assessing the state of the economy in terms of the crude quantitative measure of GDP, we need to distinguish between 'good' growth and 'bad' growth and then increase the former at the expense of the latter... From the ecological point of view, the distinction between 'good' and 'bad' economic growth is obvious. Bad growth is growth of production processes and services which externalize social and environmental costs, that are based on fossil fuels, involve toxic substances, deplete our natural resources, and degrade the Earth's ecosystems. Good growth is growth of more efficient production processes and services which fully internalize costs that involve renewable energies, zero emissions, continual recycling of natural resources, and restoration of the Earth's ecosystems (2009: 9).

There are models available for such a transition. Goals on this level will require profound shifts in governance systems and corporate culture that could be facilitated by design - if design is liberated from current market "imperatives". The design of the economic system itself is the primary design problem. Readers of this journal will be aware that the theory of design offered by Tony Fry's "designing of the designed' and Anne-Marie Willis "ontological design" is relevant here as will be explored briefly towards the end of this paper. 


\section{Feedback Failure: Distortions of Knowledge and Reason}

Design relies on accurate information to create solutions and yet both knowledge and reason suffer when market processes determine what is valid knowledge and ways of reasoning. Increasingly within neoliberal versions of capitalism the market determines what is communicated, taught and published. Design skills are needed to serve capitalism's goals and thus design is implicated in both the design of unsustainable products and the misrepresentation of the environmental consequences of unsustainable economic growth. The denial of context is perpetuated by design that embeds epistemological error into design artifacts and communications. Self-reinforcing feedback loops in communication systems including the mainstream media keep scientific and environmental knowledge marginalized. For example, sustainability requires decreasing resource use, but decreasing consumption threatens the profitability of industry. Thus industry and neoliberal governments supporting the interests of industry work strategically to prevent engagement with solutions to the ecological crisis that involves less consumption (with a few well publicized token exceptions). Because the market is narrowly focused on profit, it suppresses information that threatens its own capacity to increase profits - sometimes actively (with misleading advertising and the climate denial industry) but more often passively (such as creating conditions where honest communication of environmental science is marginalized to the point of obscurity). Designers are employed to facilitate these processes.

Design skills are harnessed for commercial imperatives. Designers working for the global brands are rewarded with large salaries. When designers attempt to address social and ecological problems, problems outside work dictated by the market, problems with no clear consumer or client, they struggle to exist within the dynamic of the market economy. In 


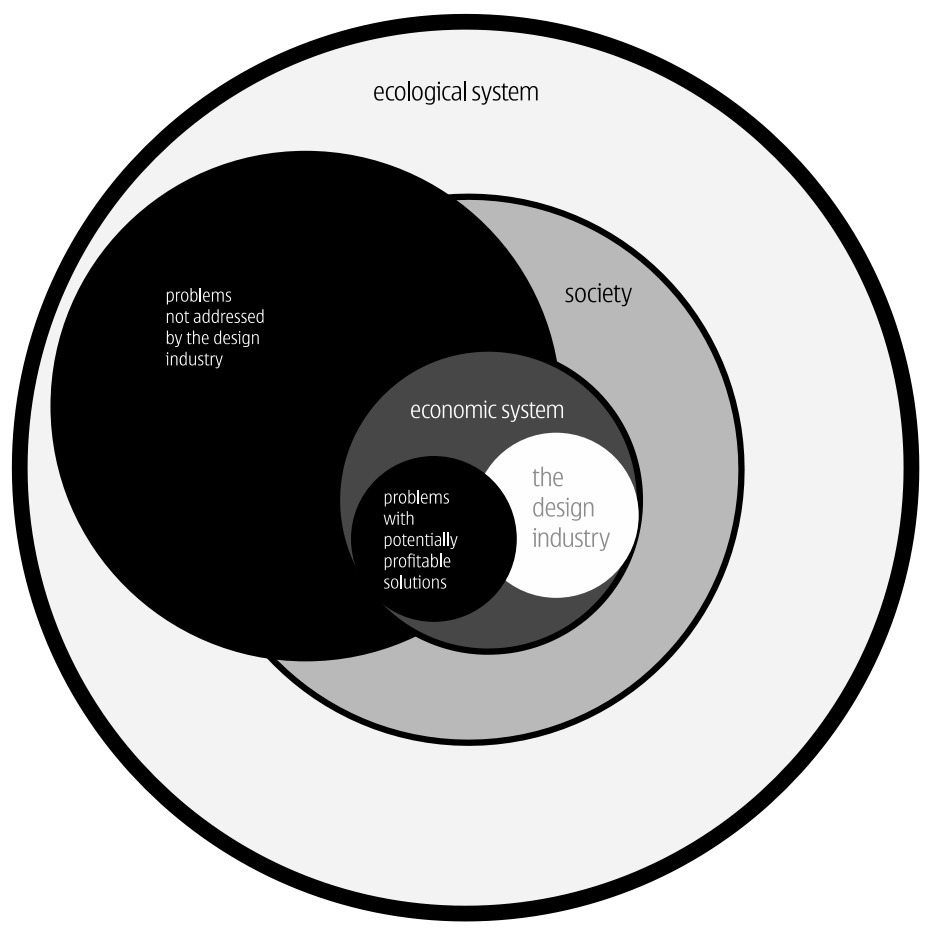

Fig 3. Problems not addressed by design. EcoLabs 2014

addressing social and ecological problems, designers expose themselves to financial ruin as there are often no commercial clients who will pay for the work of protecting communities and the environment. Market valuation processes reflect neither the social nor ecological costs, i.e. the externalities of products and services ${ }^{1}$. Design skills are applied towards socially or ecologically beneficial causes as an exception to the rule rather than as an integral part of each design brief. Designers must work outside of the market to develop ecologically and socially beneficial projects. The space to do this becomes increasingly precarious as wealth is concentrated and neoliberal policies enable new corporate enclosures on common resources (i.e. privatization of public institutions and the ecological commons). The failure of the design industry to reflect priorities associated with preserving the planet and creating healthy communities creates stark choices for individual designers who want to address systemic problems but are forced to earn a living by perpetuating destructive market processes.

Environmental communication is one of the areas where the distortion of knowledge by capitalist dynamics is most dramatic. For example, communication by environmental organizations is minuscule in comparison to those produced by corporate communication. The advertising industry creates a very different representation of the capacity of the natural world to tolerate industrial exploitation than organizations with environmental concerns. Industry has plentiful resources to communicate a view of nature that suits its own needs. For example, the UK 
advertising industry was worth $£ 17,318 \mathrm{~m}$ in 2008 (equaling approximately $1.2 \%$ of UK GDP) (World Advertising Research Center 2009: 7). The advertising industry uses the talents of visual communicators to illustrate the green credentials of their own products and brands while also attempting to reassure audiences that business as usual is morally sound. The visibility of corporate advertising marginalizes environmental concerns to the point of obscurity while creating a characterization of nature as infinitely exploitable.

In contrast to the money available to corporate advertising, the three largest campaigning environmental NGOs in the UK (WWF, Friends of the Earth and Greenpeace) have less than have $0.04 \%$ of the gross advertising expenditure of corporate advertising to establish a visibility in the public domain (Caritas Data 2011: 8.893, 6.3, 8.337; Boehnert 2012: 129). While NGOs are able to leverage their causes due to the gravitas of their mission and thus in some media environmental discourses are visible without the support of environmental NGO sponsorship, this visibility is higher only in some types of media. This media does not have the scope of commercial advertising. It reaches only those who read environmental news or watch environmental documentaries. Corporate advertising is a primary way of sense-making in a market-dominated society. Since advertising creates representations of nature that suit its own purposes (i.e. promoting continued unsustainable development), this is the dominant type of information about the environment that many citizens receive. Herein lies a basic failure in social communication systems due to the hegemony of the market. The result is a severe distortion of knowledge in the public's perception of the conditions of the natural world and associated risks to civilization.

Within the value systems, worldviews and distorted reasoning reproduced by the advertising industry, corporate media and corporate communication, there appears to be no alternative to dominant values established within neoliberal capitalism. The idea that there is no alternative to the current regime is inconsistent with anthropological, sociological and historical knowledge about values systems and political alternatives as documented by scholars such as David Graeber (2011) and Elinor Ostrom (1990). Values are learnt beliefs developed by socialization. It is disingenuous to argue that there are no alternatives. Marketing is a billion-dollar industry precisely because it is extraordinarily effective at influencing behavior and value systems. Designers participate in creating and reinforcing values. People internalize values that are part of the cultural environment, often uncritically. While communication channels such as social media offer a means to resist this corporate messaging, dominant communication channels reinforce the lie that business as usual can continue into perpetuity.

\section{Redesigning the Design Industry}

Design as a directive force could play a powerful role in helping social movements transform structurally unsustainable systems of governance. Designers can direct 
their attention to movements working towards political change. Models for transformative design can be found in Tony Fry's notion of redirected design (2009) and Anne Marie Willis' ontological design (2006) which both describes a powerful and curative role for design once a strong directional change is enacted. Fry's redirected design visions a practice of design that ends its complicity with the creation of defuturing conditions. Redirected design is informed design intelligence, an "ecology of mind able to provide a way of reading, knowing and informing actions" (Fry 2009: 11) and an ability to think relationally (Fry 2009: 39). With this perspective, design can become a means of achieving fundamental shift, but only once "designers place the current needs of the market in second place to the politico-ethical project of gaining sustain ability...." (Fry 2009: 46). This reorientation toward basic social and ecological values over short-term profit for those with capital remains the most essential design problem. Redirected design practice can be a powerful means to mobilize powerful arguments, deliver practical results and overcome resistances (Fry 2009: 47) where designers redesign the nature of their own practices by facilitating the creation of new social institutions. As part of this re-direction, designers must learn to approach complexity without negating the complex (Willis 2010: 2). Design must harness its tools and strategies towards building the social capacities to address the central design problem, the design of the market economy itself.

Many ecological theorists have stressed the critical role of design in transforming unsustainable ways of living. Sustainability educator David Orr, who coined the term ecological literacy (1992) explains that environmental problems "are mostly the result of a miscalculation between human intention and ecological results, which is to say that they are a kind of design failure" (2002: 14). These design failures signal "inherent problems in our perceptual and mental abilities" but also suggest that improvements can be made through design (2002: 14). Making "knowledge conform to ecological realities" (2002: 162) is a basic imperative for designers committed to redirected design. Design must function as a means for revealing ecological relations and changing ideas and behavior to create ways of living that prioritize sustainable imperatives. Design is well positioned to do this work. Design is a practice that has always created tools with the intention of changing ideas and behavior. Buckminster Fuller said: "If you want to change how someone thinks... Give them a tool, the use of which will lead them to think differently" (Fuller quoted in Ehrenfeld 2008: xiv). Design could be a powerful means of enacting transformational change once directed towards priorities beyond those emphasized by the design industry. 


\section{Conclusion}

Design is a practice oriented towards creating new ways of living to increase wellbeing, prosperity and to supposedly to sustain civilization over time. Design aspires to do this by attention to context and through its ability to respond using tacit knowledge to develop appropriate solutions. Despite these aspirational goals, in practice most designs solutions start with the identification of a potential for profit-making by servicing the desires of those with expendable capital. Meanwhile, the design industry and the entire capitalist system depends on the ecological system for stability, raw materials and productive capacities, on people for labor and society for stable markets. Despite these basic facts, the current economic regime (increasingly a neoliberal version of capitalism) systemically ignores the ecological and social spheres that provide the context for wealth creation. Herein is a dangerous tension between the economic system and the ecological-social systems; the design industry and design; the design agency and the individual designer with a conscience.

The redesign of industrial systems is possible but this renewal is of a higher order than the priorities and the assumptions designed into the dynamics of capitalism. This paper has described how capitalism obscures and systemically ignores the context that makes its processes possible. The design industry is situated in this interface between the market and an emerging community of practitioners increasingly capable of designing sustainability into the system (in theory) but unable to do so (in practice). While many individual designers are increasingly aware of our ecological context, they struggle to materialize these priorities within a capitalism system predominately oblivious to environmental concerns.

Despite the fact that humankind has the knowledge and resources to address environmental crisis conditions, we have not yet been able to organize ourselves to make this happen. Weak approaches to sustainability determine that climate change and biodiversity loss are increasingly in a state of crisis. This paper describes why we must delve deeply into our philosophical tradition underlying the dynamics of our political-economic system to resolve the fundamental epistemological error that denies human-nature relations and then transform the political institutions that reproduce this error. Once this error in premises is acknowledged, our current model of development is revealed as fundamentally flawed. Sustainability is literally impossible without challenging the order that systematically de-prioritizes ecological values. The current situation can be changed once a critical mass decides that our political system's values and priorities are no longer fit for purpose and acts decisively on this knowledge. Designers can be a critical part of this movement by harnessing their skills to disrupt and replace the neoliberal order. Without a doubt, this is the most dramatic challenge and imperative ever faced by design. 


\section{References}

Archer, B. 1995. The Nature of Research, Co-Design, Jan. 1995: 6-13.

Assadourian, E. 2010. The Rise and Fall of Consumer Culture, in World Watch Institute ed. 2010 State of the World: Transforming Cultures. London: W.W. Norton \& Company.

Barry, A. M. 1997. Visual intelligence: Perception, image, and manipulation in visual communication. Albany, NY: SUNY Press.

Bateson, G. 1972. Steps to an Ecology of Mind. Chicago: University of Chicago Press.

Bateson, G. 1980. Mind and Nature. London: Bantam Books.

Block, F. 2001. Introduction in Polanyi, K. [1944] The Great Transformation Boston, Beacon Press, pp. xviii-xxxviii.

Boehnert, J. 2012. "The Visual Communication of Ecological Literacy: Designing, Learning and Emergent Ecological Perception." Ph.D. Thesis, University of Brighton, Brighton.

Boehnert, J. 2015. The Green Economy: Re-conceptualizing the Natural Commons as Natural Capital. Environmental Communication (in press).

Chabris, C.F. \& Kosslyn S.M. 2005. "Representational Correspondence as a Basic Principle of Diagram Design". In S.O. Tergan and T. Keller (Eds.), Knowledge and Information Visualization, LNCS 3426, pp. 36-57.

Capra, F. 2003. The Hidden Connections. London: Flamingo.

Capra, F. \& Henderson, H. 2009. Qualitative Growth. London: The Institute of Chartered Accountants in England and Wales.

Caritas Data. 2011. Top 3000 Charities 2011/2012. London: Caritas Data.

Cross, N. 1990. The Nature and Nurture of Design Ability. Design Studies, 11: 127-140.

Daly, H. 2008. A Steady-State Economy. London: Sustainable Development Commission.

Ehrenfeld, J. 2008. Sustainability by Design. London: Yale University Press.

Fry, T. 2009. Design Futuring. Oxford: Berg. 2009.

Graeber, D. 2011. Debt: The First 5000 Years. Brooklyn, N.Y.: Melville House.

Gunter, C., Folke, G. 1993. "Characteristics of Nested Living Systems”. Journal of Biological Systems, 1(3): 257-274.

Horn, R. 1998. Visual Language: Global Communication for the 21st Century. Brainbridge Island: Macro VU Press.

IPCC. 2013. IPCC Fifth Assessment Report: Climate Change 2013. Cambridge, United Kingdom and New York, NY, USA: Cambridge University Press.

MA Board of Reviewers. 2005. Millennium Ecosystem Assessment (2005). Living beyond our means: Natural assets and human wellbeing. Washington: Island Press.

McLuhan, M. 2001 [1964]. Understanding Media. London: Routledge.

Merchant, C. 1980. "The Death of Nature", in M.Zimmerman, J.B Callicott, G.Sessions, K.Warren, J.Clark ed.. 2001. Environmental Philosophy, 3rd ed.. New Jersey: Prentice Hall. 
Orr, D. 1992. Ecological Literacy. Albany: State of New York Press.

Orr, D. 2002. The Nature of Design. Oxford: Oxford University Press.

Ostrom, E. 1990. Governing the Commons. Cambridge: Cambridge University Press.

Polanyi, K. 2001 [1944] The Great Transformation Boston, Beacon Press.

Plumwood, V. 2002. Environmental Culture. Oxon: Routledge.

Rockström, J. et al. 2009. Planetary Boundaries: Exploring the Safe Operating space for Humanity. Ecology and Society 14(2): 32.

Rushkoff, D. 1996. Media Virus. London: Ballantine Books.

Santos, B.S. 2007. Cognitive Justice in a Global World. Plymouth: Lexington Books.

Shiva, V. 1988. Reductionist Science as Epistemological Violence. In Ashis Nandy (ed.) Science, Hegemony and Violence. Oxford: Oxford University Press.

Simms, A., Johnson, V. \& Chowla, P. (2010). Growth Isn't Possible. London: new economics foundation.

Smith, R. 2007. Carpe Diem: The Dangers of Risk Aversion, Lloyd's Register Educational Trust Lecture. 29 May 2007.

Stiglitz, J. 2001. Foreword in Polanyi, K. [1944] The Great Transformation Boston, Beacon Press, pp. vii-xvii.

Sterling, S. 2001. Sustainable Education—Re-visioning Learning and Change, Schumacher Briefing no. 6. Dartington: Schumacher Society/Green Books.

Stern, N. 2007. The economics of climate change - The Stern review. Cambridge University Press, Cambridge, UK.

Willis, A.M. 2006. Ontological Designing - laying the ground. Design Philosophy Papers Collection Three: 80-98.

Willis, A.M. 2010. Can Complexity be Contained? Design and Complexity Conference 2010. 7-9 July 2010, University of Montreal. Montreal: Design Research Society.

World Advertising Research Center. 2009. The Advertising Statistics Yearbook 2009. 27 ${ }^{\text {th }}$ Edition. Henley on Thames: World Advertising Research Center.

WWF-UK. 2010. Annual Report 2010. Godalming, UK: WWF-UK.

WWF International. 2010. The Living Planet Report 2010. Gland, Switzerland: WWFInternational. 
${ }^{1}$ Even when ecological spaces and social impacts are given a financial value (and there is an United Nations led movement working towards assigning financial valuations to ecosystem services) these financial valuation processes never actually function to protect the environment since the financial industry works with a very different logic to the ecological system in which it is embedded. It is error in type to use the logic of a subsystem (the economy) to value another system (the ecological system) on which the subsystem is dependent (Boehnert 2015). 